\title{
Microstructure and Properties of Al-Mg-Si-Li Alloys with Different Mg Content
}

\author{
ZHAO Zhongkui ${ }^{1,2, a^{*}}$, GAO Qing ${ }^{1, b}$, YAO Yu ${ }^{1, \mathrm{c}}$, LIU Bozu ${ }^{1, \mathrm{~d}}$, ZHANG Di ${ }^{1, \mathrm{e}}$ and \\ WANG Quiqing ${ }^{1,2, f}$
}

${ }^{1}$ Materials Science and Engineering School, Shandong Jianzhu University, Jinan, PR China, 250101

${ }^{2}$ Shandong Engineering Research center for Clean foundry, Jinan, PR China, 250101

ajorezhk@163.com, ’s sdbzgaoqing@163.com, c1471990010@qq.com, 'liubozu@163.com,

2693404644@qq.com, wangguiqing@126.com

*Zhong-Kui ZHAO, jorezhk@163.com

Keywords: Mg content; Al-Mg-Si-Li alloys; Microstructure; Properties.

Abstract. Microstructure and properties of $\mathrm{Al}-\mathrm{Mg}$-Si-Li alloys with different $\mathrm{Mg}$ content were investigated. The microstructure was observed by optical microscopy, the phases were determined by X-rays diffractometry, the hardness was monitored by Vickers, the mechanical properties were determined by tensile tester, fracture morphology was conducted by scanning electron microscopy. The tensile strength and the elongation of the Al-Si-Li alloys is improved by the addition of magnesium. With the increment of $\mathrm{Mg}$ content, the $\alpha$ - $\mathrm{Al}$ is refined, the amount of primary Si decreases, the eutectic increases, and the mechanical properties of the alloys are improved. The alloys containing $3.0 \mathrm{wt}$. $\% \mathrm{Mg}$ has excellent strength and elongation. If the $\mathrm{Mg}$ content is too much, the alloys have poor mechanical properties as Chinese script $\mathrm{Mg}_{2} \mathrm{Si}$ are present.

\section{Introduction}

Magnesium is an alloying element that is usually added to Al-Si casting alloys to enhance the mechanical properties of the alloys. Though the yield strength of the alloys is improved by the increment of $\mathrm{Mg}$ content, both the tensile ductility and the strength are reduced when $\mathrm{Mg}$ content is beyond $0.7 \mathrm{wt} . \%$ [1]. Polyhedral primary particles and as Chinese script $\mathrm{Mg}_{2} \mathrm{Si}$ phases were observed, the volume fraction and size of the primary $\mathrm{Mg}_{2} \mathrm{Si}$ particles was incresed with increasing the $\mathrm{Mg}$ content [2]. The magnesium content of $\mathrm{Al}-\mathrm{Si}-\mathrm{Mg}$ alloys is usually from $0.5 \mathrm{wt}$. $\%$ to $3.0 \mathrm{wt} . \%$ since too much magnesium may reduce properties of the alloys. Lithium is added to Al-Si alloys to decrease the density and to improve the specific strength and the elastic modulus. Al-Si-Li alloys provides a new series of aluminum alloys system containing high lithium, however, the series of alloys were much less investigated in domestic. Dubost Bruno had developed Al-Si-Li alloys containing 3.6-8wt.\%Li and 5-14wt.\%Si by rapid solidification technique [3], which provided globular primary AlLiSi in a fully divorced AlLiSi/ $\alpha$-Al eutectic structure [4], the alloys has low density, high elastic modulus and high ratio modulus. The triangle and oval primary Si phases appeared in the microstructure of Al-Si-Mg- $x \mathrm{Li}$ alloys, the precipitation was inhibited to make the alloys have lower elongation and strength [5]. In order to improve the mechanical properties of $\mathrm{Al}-\mathrm{Si}-\mathrm{Mg}-\mathrm{Li}$ alloys, the $\mathrm{Mg}$ content of $\mathrm{Al}-\mathrm{Si}-\mathrm{Mg}-\mathrm{Li}$ alloys was modified, and the microstructure and mechanical properties of $\mathrm{Al}-\mathrm{Si}-\mathrm{Mg}-\mathrm{Li}$ alloys with different $\mathrm{Mg}$ content was investigated in the paper.

\section{Experimental}

Composition of the alloys studied is shown in table 1, which were melted in a vacuum furnace and cast in a metal mould under argon. The alloys were solutionized at $530^{\circ} \mathrm{C}$ for $30 \mathrm{~min}$, and then quenched into water. The solutions were artificially aged at $200^{\circ} \mathrm{C}$.

Microstructure of the alloys was observed by optical microscopy. Hardness was monitored by Vickers using loads of $0.1 \mathrm{~kg}$. The different phase of alloys was analyzed using X-rays diffractometry. The tensile 
strength was determined by the tensile tester at the constant rate of $1 \mathrm{~mm} / \mathrm{s}$ using the bars of $10 \mathrm{~mm}$ in diameter and 50mm in length. The fracture morphology was analyzed by scanning electron microscopy (SEM).

Table 1. Chemical composition of the tested alloys[wt.\%]

\begin{tabular}{ccccc}
\hline Item & $\mathrm{Si}$ & $\mathrm{Li}$ & $\mathrm{Mg}$ & $\mathrm{Al}$ \\
\hline 1 & 7.0 & 0.9 & 0 & Balance \\
2 & 7.0 & 0.9 & 0.3 & Balance \\
3 & 7.0 & 0.9 & 3.0 & Balance \\
4 & 7.0 & 0.9 & 5.0 & Balance \\
\hline
\end{tabular}

\section{Results}

Microstructure of as-cast Al-Si-Mg-Li alloys with different Mg content. Figure 1 shows the as-cast microstructure of Al-Si-Mg-Lialloys with different $\mathrm{Mg}$ content. From the microstructure of as-cast Al-Si-Li alloy with $\mathrm{Mg}$-free, it is observed that a few of fine $\tau_{1}$-AlLiSi particles are trapped in the dendritic $\alpha$ - $\mathrm{Al}$ matrix, and $\mathrm{Al}+\mathrm{Si}+\tau_{1}-\mathrm{AlLiSi}$ eutectic is present in interdendritic regions, as shown in Figure 1(a). The massive and coarese primary Si phase is present, the amount of the eutectic decreases, and the $\tau_{1} \mathrm{~T}-\mathrm{AlLiSi}$ or $\mathrm{Mg}_{2} \mathrm{Si}$ particles in the $\alpha$-Al phase are coarsened when $\mathrm{Mg}$ content is $0.3 \%$, as shown in Figure 1(b). The dendritic $\alpha$ - $\mathrm{Al}$ has been refined, more $\mathrm{Al}-\mathrm{Mg}_{2} \mathrm{Si}-\mathrm{AlLiSi}$ eutectic is formed in interdendritic regions, and almost no primary $\mathrm{Si}$ is present in the alloy containing $3.0 \% \mathrm{Mg}$, as shown in Figure 1(c). From Figure 1(d), it is observed that block Si and as Chinese script microstructures are present, however, the eutectic decreases.

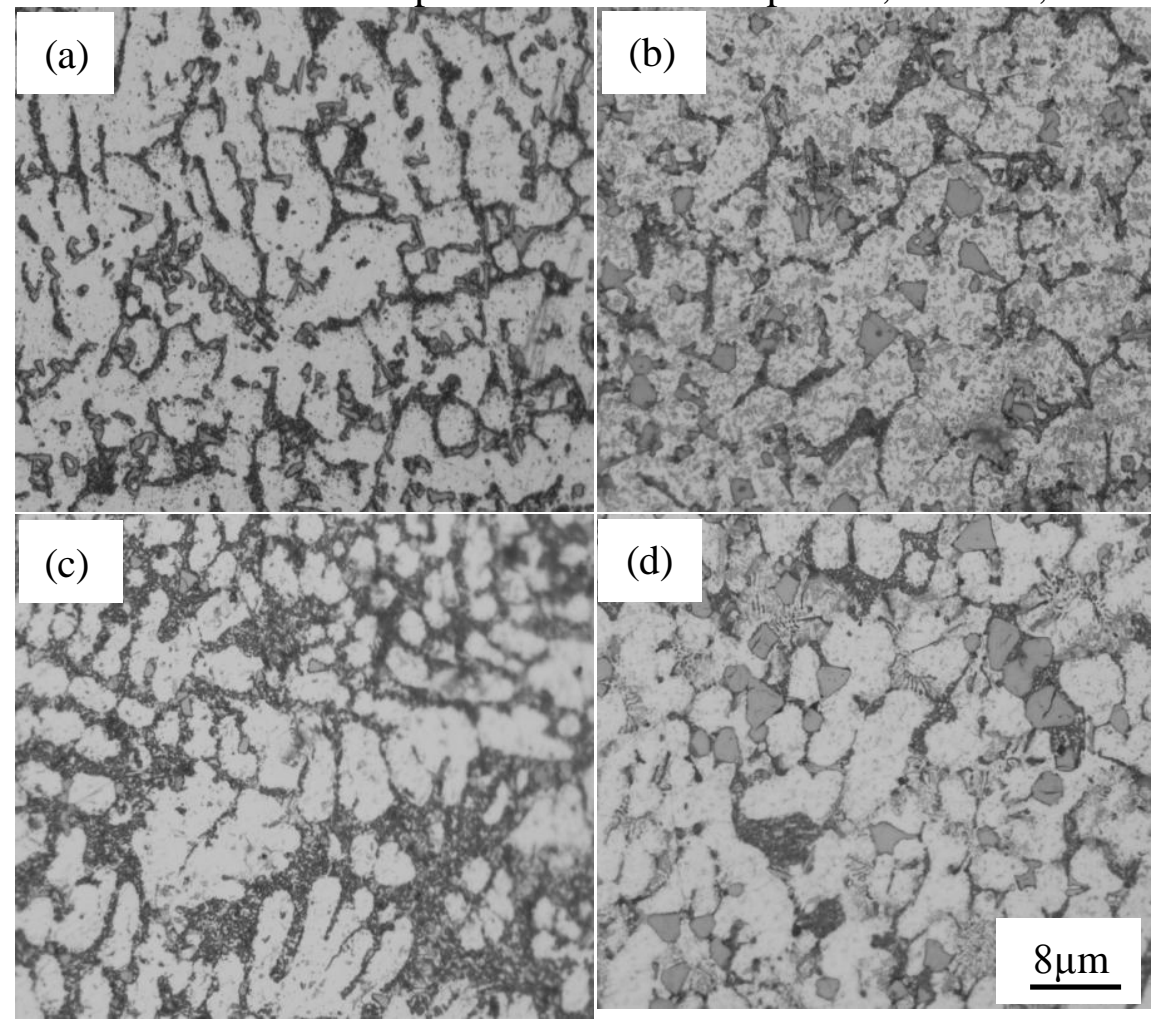

Figure 1 Microstructure of as-cast of Al-Si-Mg-Li alloys with

(a) $\mathrm{Mg}$-free, (b) $0.3 \% \mathrm{Mg}$, (c) $3.0 \% \mathrm{Mg}$, (d) $5.0 \% \mathrm{Mg}$

Aging Properties. Figure 2 shows the Vickers hardness of Al-Si-Mg-Li alloys with different $\mathrm{Mg}$ content. For the as-cast alloys, though the alloys are hardened when $0.3 \mathrm{wt} . \% \mathrm{Mg}$ is added, the hardness of alloys keep low value, and there is alomst no change in hardness as the $\mathrm{Mg}$ content increases. For the alloys aged at $200^{\circ} \mathrm{C}$ for $24 \mathrm{~h}$, the alloys have higher value of hardness. The hardness is improved quickly first, and then the hardness value increases linerly with the increment of $\mathrm{Mg}$ content when $\mathrm{Mg}$ content is beyond $0.3 \mathrm{wt} . \%$. 


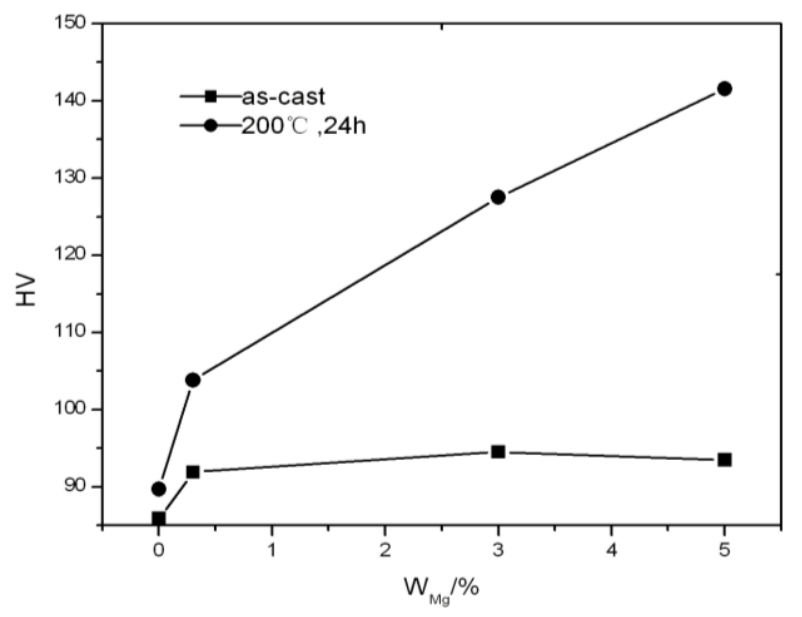

Figure 2 Hardness of the as-cast and aged $\mathrm{Al}-\mathrm{Si}-\mathrm{Mg}$-Li alloys with different $\mathrm{Mg}$ content

$\mathrm{X}$-ray diffractometry. Figure 3 shows $\mathrm{X}$-rays diffraction of $\mathrm{Al}-7.0 \% \mathrm{Si}-0.3 \% \mathrm{Mg}-1.1 \% \mathrm{Li}$ alloy. It is found that $\alpha-\mathrm{Al}, \mathrm{Si}$ and AlLiSi are present in the tested alloy. The $\mathrm{Mg}_{2} \mathrm{Si}$ is too little to show diffraction peak.

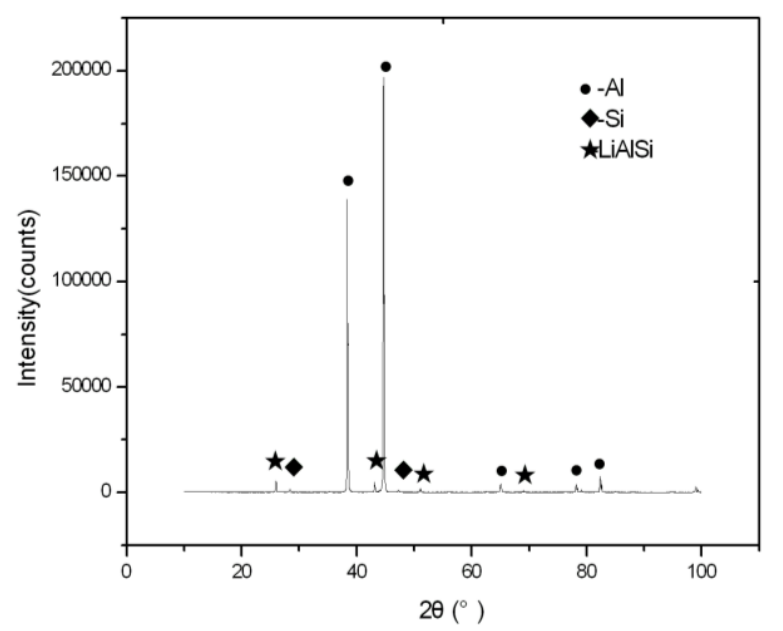

Figure $3 \mathrm{X}$-rays diffraction of $\mathrm{Al}-7.0 \% \mathrm{Si}-0.3 \% \mathrm{Mg}-1.1 \% \mathrm{Li}$ alloy

Mechanical Properties. Table 2 shows the mechanical properties of Al-Si-Mg-Li alloys with different $\mathrm{Mg}$ content. It is found that $\mathrm{Al}-\mathrm{Si}-\mathrm{Mg}-\mathrm{Li}$ alloys containing 3.0wt.\% $\mathrm{Mg}$ have excellent tensile strength, yield strength and elongation. The alloys containing $0.3 \mathrm{wt} . \% \mathrm{Mg}$ have the poorest strength, which is lower than that of the alloys $\mathrm{Mg}$ free. The strength and elongation of the alloys containing $5.0 \mathrm{wt} . \% \mathrm{Mg}$ is also lower than that of the alloys containing $3.0 \mathrm{wt} . \% \mathrm{Mg}$.

Table 2 Mechanical properties of Al-Si-Mg-Li alloys with different $\mathrm{Mg}$ content

\begin{tabular}{ccccc}
\hline Item & Mg content[wt.\%] & Tensile strength[MPa] & Yield Strength[MPa] & Elongation[\%] \\
\hline 1 & 0 & 290 & 142 & 1.4 \\
2 & 0.3 & 223 & 98 & 1.6 \\
3 & 3.0 & 298 & 174 & 1.6 \\
4 & 5.0 & 269 & 154 & 1.4 \\
\hline
\end{tabular}

Tensile fracture morphology. The tensile fracture morphology of the alloy containing $0.3 \mathrm{Mg}$ is shown in Figure 4. It is found that the tesile fracture exhibited ductile fracture with dimples. Inner surface of the dimple pits is clean, which indicates that the pits were formed by Si breaking off. 


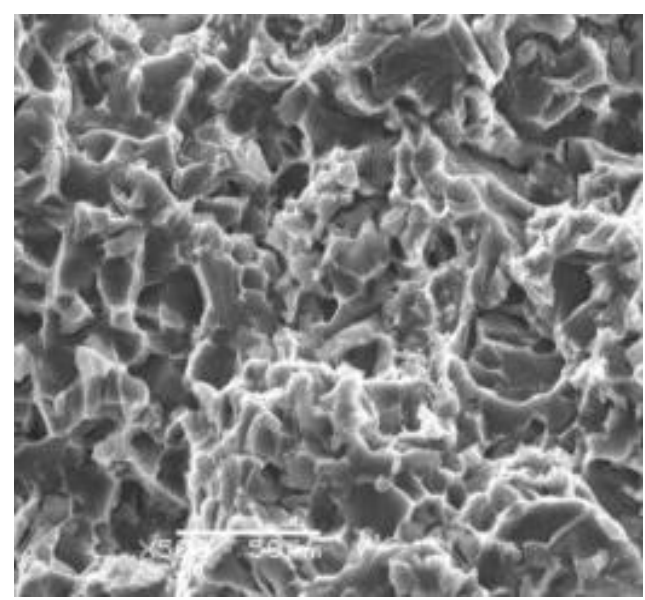

Figure 4 Tensile fracture morphology of alloys containing $0.3 \mathrm{wt} . \% \mathrm{Mg}$

\section{Discussion}

When 0.3 wt. $\% \mathrm{Mg}$ is added into the Al-Si-Li alloys, coarse $\mathrm{Si}$ is present on the $\alpha$ - $\mathrm{Al}$ matrix, which corresponds to the eutectic reduction in the former interdendrite of the cast structure. In Al-Si-Li alloys, $\tau_{1}$-AILiSi is primary phase[Gröbner2001], and $\mathrm{Mg}_{2} \mathrm{Si}$ particles are the main strengthening precipitates in the $\mathrm{Al}-\mathrm{Si}-\mathrm{Mg}$. The alloys containing $3.0 \mathrm{wt} . \% \mathrm{Mg}$ have ternary eutectic among boundary of dendrite, and almost no primari $\mathrm{Si}$ is present. The ternary eutectic is A-AlLiSi- $\mathrm{Mg}_{2} \mathrm{Si}$.

$\mathrm{Be}$ aged, the $\mathrm{Mg}_{2} \mathrm{Si}$ precipitates does not strengthen signicantly the alloys containing $0.3 \mathrm{wt} \% \mathrm{Mg}$. However, the precipitates of the metastable $\mathrm{Mg}_{2} \mathrm{Si}$ phase produces the dramatic strengthening of the alloys as the $\mathrm{Mg}$ content of ageing is increased. The effect of the aging on the hardness of the alloys is of course dramatic. It has shown that the evolution of strength is mainly controlled by the microstructure. The maximum value of strength is determined by the amount of eutectic and $\mathrm{Si}$.

A detailed analysis of the microstructure evolution for different $\mathrm{Mg}$ content and heat treatments, coupled with a fractography analysis of the elementary failure modes allows to understand the main reasons for the evolution in the strength and elongation in the Al-Si-Mg-Li alloys. The spatial distribution of constituent $\mathrm{Si}$ particles has been identified as the main cause of low elongation. Intergranular Si weakens the strength of the grain boundaries, together with the evolution of the aging-hardening capability of the alloys depending on the state of precipitation. The coarse intragranular Si appears to play a key role in the reduction of the strentgh and elongation.

\section{Conclusions}

The tensile strength and the elongation of the Al-Si-Li alloys is improved with the addition of magnesium. With the increment of $\mathrm{Mg}$ content, the $\alpha-\mathrm{Al}$ is refined, the amount of primary Si decreases, the eutectic increases, and the mechanical properties of the alloys are improved. The alloys containing $3.0 \mathrm{wt} . \% \mathrm{Mg}$ have excellent strength and elongation. However, if the $\mathrm{Mg}$ content is too much, the alloys have poor mechanical properties as Chinese script $\mathrm{Mg}_{2} \mathrm{Si}$ are present.

\section{Acknowledgement}

This research was financially supported by the Shandong Provincial Natural Science foundation, (ZR2012EMM013 and ZR2012EMM014). 


\section{References}

[1] C. H. Caceres, C. J. Davidson, J. R. Griffiths, Q. G. Wang, The effect of Mg on the microstructure and mechanical behavior of Al-Si-Mg casting alloys, Metallurgical and Materials Transactions A. 30(1999) 2611-2618

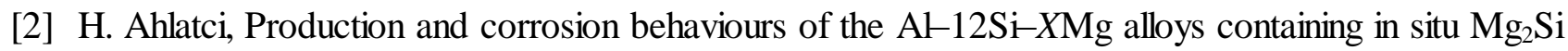
particles, Journal of Alloys and Compounds. 503(2010)122-126.

[3] B. Dubost, European patent 208,631.(1987)

[4] C. Banjongprasert, S.C. Hogg, I.G. Palmer, N. Grennan-Heaven, I.C. Stone, P. S. Grant, Spray Forming of Al-Fe-Cr-Ti and Al-Si-Li Alloys, in: Y.W. Chang, N.J. Kim, C.S. Lee (Eds.), Materials Science Forum, Trans. Tech. Publications Ltd., Switzerland, 2007, pp.1075-1078.

[5] J. Gröbner, D. Kevorkov, R. Schmid-Fetze, The Al-Li-Si System: 2. Experimental Study and Thermodynamic Calculation of the Polythermal Equilibria, Journal of Solid State Chemistry. 156(2001)506-511. 